\title{
EFFECT OF SILYMARIN EXTRACTED FROM SILYBUM MARIANUM ON NICKEL HEMATOTOXICITY AND NEPHROTOXICITY IN MALE ALBINO WISTAR RATS
}

\author{
SAMIRA BOUHALIT'1 ${ }^{1}$ ZINE KECHRID ${ }^{1}$, ABDELFATTAH ELFEKI ${ }^{2}$ \\ ${ }^{1}$ Laboratory of Applied Biochemistry and Microbiology, Department of Biochemistry, Faculty of Sciences, University of Annaba, 23000 \\ Annaba, Algeria, ${ }^{2}$ Laboratory of Ecophysiology animal, Faculty of Science, University of Sfax, 3038 Sfax, Tunisia \\ Email: kechridzine@yahoo.fr \\ Received: 05 Mar 2017 Revised and Accepted: 19 Jun 2017
}

\begin{abstract}
Objective: The objective of this study was to investigate the effect of silymarin extract from Silybum marianum against nickel-induced alterations in haematological indices, kidney dysfunction and renal antioxidant defence system.

Methods: Male albino Wistar rats were divided into four groups seven each. Control, silymarin, nickel and nickel plus silymarin. Silymarin was administrated orally (100 mg/kg b. wt) and nickel as nickel sulfate $\left(\mathrm{NiSO}_{4} 6 \mathrm{H}_{2} 0\right)$ was given intraperitoneally (20 mg/kg b. wt) at alternative days. The experiment continued for three consecutive weeks. Body weight was recorded regularly. After overnight fasting, animals were killed and serum creatinine, serum urea, serum uric acid, hematological parameters and renal antioxidant markers were determined.

Results: The treatment with nickel led to a significant decrease in body weight with an increase in both absolute and relative kidney weights and a significant increase in renal markers, which confirmed by histopathological alteration. A microcytic anemia was also observed, which was manifested by a reduction of red blood cells count (RBC), hemoglobin ( $\mathrm{Hb}$ ) concentration, platelet counts (Plt), hematocrit and white blood cells counts (WBC). The level of lipid peroxidation was increased. Whereas, GSH concentration and enzymatic antioxidants SOD, GSH-Px and CAT activities were decreased. The co-treatment with methanolic extract of milk thistle attenuated the variation in the hematological and renal markers, decreasing renal lipid peroxidation $(\mathrm{p}<0.05)$ with a concomitant increasing reduced glutathione content $(\mathrm{p}<0.01)$ and restoring the antioxidant enzymes (SOD, CAT, GSH-Px) in kidney, as well as an improvement in histological changes compared to those previously noticed in nickel group.
\end{abstract}

Conclusion: To conclude, these findings demonstrated that silymarin extract effectively improved heamatotoxicity and nephrotoxicity caused by nickel.

Keywords: Nickel, Silymarin, Heamatotoxicity, Nephrotoxicity, Stress Oxidant

(C) 2017 The Authors. Published by Innovare Academic Sciences Pvt Ltd. This is an open access article under the CC BY license (http://creativecommons.org/licenses/by/4.0/) DOI: http://dx.doi.org/10.22159/ijpps.2017v9i8.18293

\section{INTRODUCTION}

Nickel (Ni) is a metallic element that is naturally present in the earth's crust. Due to the unique physical and chemical properties, metallic nickel and its compounds are widely used in modern industry. Therefore, humans and animals are exposed to nickel via, occupational and environmental setting occurs chiefly through smelting, mining, electroplating, refining operation during manufacture of steel and other alloys, batteries, paints and medical implants [1]. High quantity of nickel has been reported to cause various toxicities such as pulmonary, renal and cardiovascular effects [2]. Carcinogenic and mutagenic potential of nickel were also demonstrated [3]. This element is transported by blood and is retained by various tissues or excreted, mainly through urine, making thus the kidney the most target organ of nickel toxicity and carcinogenicity [4]. Studies in the distribution of nickel following acute i. p. injection of nickel in rats showed that the highest accumulation of nickel was in the kidney [5]. Toxic nephropathy with proteinuria, amino acid urea, reduced urea clearance, morphologic changes in the kidney glomerulus and proximal tubules have been also observed [6]. The most plausible mechanism of nickel toxicity by which causes cell death or damages the genetic material involves oxidative stress, which leads to lipid peroxidation and oxidation of both DNA and proteins, which results finally in cell apoptosis and nephrotoxicity [7, 8]. Nickel was found also to be harmful for hematopoiesis and female reproduction [9]. The heamtotoxic effects include chromosomal abnormalities of the bone marrow and hematopoietic system $[3,10]$. The toxic effects of nickel might be prevented by some exogenous supplementation of antioxidant compounds, which play an important role against the adverse effects of reactive oxygen and nitrogen species [11]. Silymarin is a standardized mixture of antioxidant flavonolignans extracted from the seeds of Silybum marianum (L.) Gaertn. (milk thistle plant, Asteraceae). [12]. It is a free radical scavenger and a membrane stabilizer that prevents lipoperoxidation and reduced glutathione depletion in some experimental models [13]. It has been also reported that having multiple pharmacological activities including hepatoprotectant, an anti-inflammatory agent, antibacterial, anti-allergic, antiviral, anti mutagenic, antineoplastic, and antithrombotic agent [14]. Silymarin is widely used for hepatic and biliary disorders [15]. Thus, the present investigation was undertaken to evaluate the protective effects of silymarin against nickel-induced hematotoxicity and nephrotoxicity.

\section{MATERIALS AND METHODS}

\section{Chemicals}

Nickel sulfate, 2-thiobarbituric acid (TBA), butylated hydroxytoluene (BHT), 5, 5'-dithiobis-2-nitrobenzoic acid (DTNB), trichloroacetic acid (TCA), nitro blue tetrazolium (NBT), 1-chloro 2, 4-dintrobenzene (CDNB) were obtained from Sigma Chemical Co. (St. Louis, France) and all other chemicals were of analytical grade.

\section{Plant extracts preparation}

The seeds of Silybum marianum were collected from North-East of Algeria (Guelma Province), during summer 2012. The plant was identified by the Department of Botany. The fruits were manually separated from the heads and freed of the pappus, and finely powdered. Milk thistle seeds $(100 \mathrm{~g})$ were defatted with n-hexane by maceration at room temperature for overnight, then this defatted powder was extracted with $80 \%$ aqueous methanol for $72 \mathrm{~h}$ at room temperature. Extracts were filtered and concentrated using rotary evaporator. After extraction, the extract was filtered, concentrated in a rotary evaporator at a temperature not exceeding $50{ }^{\circ} \mathrm{C}$ under reduced pressure and stored in a refrigerator [16]. 


\section{Experimental design}

Male (Wistar) rats (180-220 g) were obtained from Pasteur Algiers Institute, Algeria. Animals were maintained under standard conditions of temperature and humidity with $12 \mathrm{~h}$ light/dark cycle and fed standard pellet diet and water ad-libitum for two weeks as an adaptation period. Then rats were randomly divided into four groups of seven animals each: Group I, normal control rats were administrated $1 \mathrm{ml}$ of normal saline. Group II, rats orally administered with silymarin extract $(100 \mathrm{mg} / \mathrm{kg}$, b. wt.) [17]. Group III received intra peritoneally nickel sulfate $(20 \mathrm{mg} / \mathrm{kg}$ b. wt.) on alternate days [18]. Group IV, rats treated also in the same way with both nickel sulfate and the extract of Silybum marianum simultaneously. The period of the experiment continued for three weeks. Then, animals were sacrificed by cervical decapitation after overnight fasting. Serum was separated by centrifugation for $10 \mathrm{~min}$ at $3000 \mathrm{rpm}$ and stored at $-20{ }^{\circ} \mathrm{C}$ for the biochemical analysis. The kidney was removed immediately, rinsed in ice cold saline $0.9 \%$. Then, the first kidney was homogenized in $2 \mathrm{ml}$ ice cold TBS $(50 \mathrm{mmol}$ Tris, $150 \mathrm{mmol} \mathrm{NaCl}$, $\mathrm{pH}$ 7.4). The homogenate was centrifuged at $10.000 \mathrm{~g}$ for $15 \mathrm{~min}$ at $4{ }^{\circ} \mathrm{C}$ and the resultant supernatant was frozen at- $20^{\circ} \mathrm{C}$ for oxidative parameters determination. The second kidney was fixed in $10 \%$ neutral formalin and used for histological examination.

\section{Biochemical analysis}

Uric acid, creatinine and urea as a dysfunction kidney markers were assessed using commercial diagnostic kits (Spinreact, Spain, ref: creatinine-1001111, urea-1001329 and uric acid-1001011).

\section{Hematological parameters determination}

Red blood cell (RBC) count, white blood cell (WBC) count, hemoglobin concentration ( $\mathrm{Hb})$, hematocrit and platelet count (Plt) were estimated by the electronic automate coulter MAXM (Beckman Coulter Inc. Fullerton, USA).

\section{Assessment of oxidative stress parameters \\ Lipid peroxidation (LPO) level}

The lipid peroxidation level in kidney homogenate was measured as malondialdehyde (MDA); it reacts with thiobarbituric acid (TBA) as a TBARS to produce a red coloured complex that has a peak absorbance at $532 \mathrm{~nm}$ [19]. $125 \mu \mathrm{l}$ of supernatants were mixed with $50 \mu \mathrm{l}$ of TBS and $125 \mu \mathrm{l}$ of TCA-BHT (trichloroacetic acidbutylhydroxytoluene) in order to precipitate proteins and then was centrifuged. $200 \mu \mathrm{l}$ of the new supernatants were mixed with $40 \mu \mathrm{l}$ of $\mathrm{HCl}(0.6 \mathrm{M})$ and $160 \mu \mathrm{l}$ of TBA dissolved in $26 \mathrm{mmol}$ Tris, and the mixture was heated at $80{ }^{\circ} \mathrm{C}$ for $10 \mathrm{~min}$. The absorbance of the resulting supernatants was measured at $530 \mathrm{~nm}$. The amount of MDA was calculated using a molar extinction coefficient $1.56 \times 10^{5}$ $\mathrm{M} / \mathrm{cm}$.

\section{Reduced glutathione (GSH) concentration}

Kidney GSH content was estimated using a colorimetric technique [20], which based on the development of yellow color when (DTNB) is added to compounds containing sulfhydryl groups. In brief, $0.8 \mathrm{ml}$ of homogenate supernatant was added to $0.3 \mathrm{ml}$ of $0.25 \%$ sulfosalicylic acid, and then tubes were centrifuged. Supernatant $(0.5 \mathrm{ml})$ was mixed with $0.025 \mathrm{ml}$ of $0.01 \mathrm{M}$ DTNB and $1 \mathrm{ml}$ phosphate buffer $(0.1 \mathrm{M}, \mathrm{pH}$ 7.4). Finally, the absorbance was recorded at $412 \mathrm{~nm}$. Total GSH content was expressed as nmol GSH/mg protein.

\section{Antioxidant enzymes assays}

Superoxide dismutase (SOD) activity was determined by measuring its ability to inhibit the photoreduction of NBT [21]. Catalase (CAT) activity was assayed spectrophotometrically as described by Aebi [22]; the $\mathrm{H}_{2} \mathrm{O}_{2}$ decomposition rate was followed by monitoring absorption at $240 \mathrm{~nm}$. Glutathione peroxidase activity (GSH-Px) was assayed by the method based on the reaction between glutathione remaining after the action of GSH-Px and 5, 5-dithio-bis (2-nitrobenzoic acid) to form a complex that absorbs maximally at $412 \mathrm{~nm}$ [23].

\section{Renal proteins content determination}

Protein was measured by the method of Bradford [24], using bovine serum albumin as a standard.

\section{Histological evaluation}

Histological evaluation was performed on slices of the kidney and portion of specimen fixed in $10 \%$ formalin and embedded in paraffin wax. Then sections were cut at $4 \mu \mathrm{m}$ in thickness, stained with haematoxylin and eosin and viewed under a light microscope for histological changes [25].

\section{Statistical analysis}

Data are given as means \pm SEM. Statistical significance of the results obtained for various comparisons was estimated by applying oneway analysis of variance (ANOVA) followed by Student's t-test and the level of significance was set at $\mathrm{p}<0.05$.

\section{RESULTS}

Effect of treatment on body weight, absolute and relative kidney weights

Body weight, absolute and relative kidney weights of animals subjected to different treatments were shown in table 1 . The body weight of animals exposed to nickel was decreased significantly $(p<0.01)$ as compared to control rats. Treatment with silymarin showed an improvement $(\mathrm{p}<0.05)$ in final body weight compared to nickel group. The absolute and relative kidney weights were significantly increased $(p<0.01)$ in nickel treated animals and conversely a significant decrease was noticed $(\mathrm{p}<0.01)$ in the co-treatment with silymarin.

Table 1: Effect of nickel and its combination with silymarin (Sil) on body weight, absolute and relative kidney weights

\begin{tabular}{|c|c|c|c|c|}
\hline \multirow{2}{*}{ Experimental groups } & \multicolumn{2}{|c|}{ Body weight (g) } & \multicolumn{2}{|c|}{ kidney weights } \\
\hline & Initial & Final & Absolute (g) & Relative (g/100g b. wt) \\
\hline Control & $201.33 \pm 6.5$ & $250.3 \pm 6.8$ & $0.6 \pm 0.03$ & $0.45 \pm 0.02$ \\
\hline Sil & $205.83 \pm 3.3$ & $251.7 \pm 4.5$ & $0.56 \pm 0.05$ & $0.45 \pm 0.04$ \\
\hline $\mathrm{Ni}$ & $202.33 \pm 6.9$ & $181.7 \pm 11.3^{* *}$ & $0,8 \pm 0.03^{* *}$ & $0.92 \pm 0.1^{* *}$ \\
\hline $\mathrm{Ni}+\mathrm{Sil}$ & $203 \pm 5.94$ & $228.7 \pm 6.6^{\#}$ & $0.58 \pm 0.04^{\# \#}$ & $0.50 \pm 0.04^{\# \#}$ \\
\hline
\end{tabular}

Values are given as mean \pm SEM of seven rats each group. Statistically significantly different from control: ${ }^{* *} \mathrm{p}<0.01$; from Ni: ${ }^{\#}<0.05$, ${ }^{\# \#} \mathrm{p}<0.01$

Table 2: Effect of nickel and it combination with silymarin (Sil) on serum kidney biochemical markers; creatinine, urea and uric acid after three weeks of treatment

\begin{tabular}{lll}
\hline Experimental groups & Creatinine (mg/d) & Urea (mg/dl) \\
\hline Control & $37.32 \pm 2.28$ & $5.68 \pm 0.34$ \\
$\mathrm{Sil}$ & $38.1 \pm 3.26$ & $5.88 \pm 0.49$ \\
$\mathrm{Ni}$ & $55.02 \pm 5.29^{* *}$ & $8.1 \pm 0.44^{* *}$ \\
$\mathrm{Ni}+\mathrm{Sil}$ & $31 \pm 1.32^{\# \#}$ & $5.93 \pm 0.11^{\#}$ \\
\hline
\end{tabular}

Values are given as mean \pm SEM of seven rats each group. Statistically different from control: ${ }^{* *} \mathrm{p}<0.01$; from $\mathrm{Ni}:{ }^{\#} \mathrm{p}<0.05$, ${ }^{\# \#} \mathrm{p}<0.01$. 


\section{Effects of treatments on plasma biochemical parameters}

As seen from table 2, serum creatinine, serum urea and serum uric acid levels were significantly increased $(\mathrm{p}<0.01)$ following administration of nickel compared to the control group. However, treatment with silymarin $(100 \mathrm{mg} / \mathrm{kg})$ significantly indicated amelioration in the recorded kidney function markers.

Table 3: Effect of nickel and its combination with Silymarin (Sil) on red blood cells (RBC), hematocrit, heamoglobin concentration (Hb), white blood corpuscle (WBC) and blood platelet (Plt) counts

\begin{tabular}{lllll}
\hline Groups & Red blood cells $\left(\mathbf{1 0}^{6}\right.$ cell $\left./ \boldsymbol{\mu l}\right)$ & Hematocrit $(\%)$ & Hb $(\mathbf{g} / \mathbf{d l})$ & White blood cells $\left(\mathbf{1 0}^{\mathbf{3}} \mathbf{c e l l} / \boldsymbol{\mu l}\right)$ \\
\hline Control & $9.47 \pm 0.18$ & $50.55 \pm 1.04$ & $17.3 \pm 1.2$ & $11.75 \pm 0.52$ \\
$\mathrm{Sil}$ & $8.56 \pm 0.26$ & $45.88 \pm 1.44^{*}$ & $16.4 \pm 0.7$ & $11.5 \pm 1.22$ \\
$\mathrm{Ni}$ & $5.9 \pm 0.2^{* * *}$ & $33.7 \pm 2.64^{* * *}$ & $11.02 \pm 0.53^{* *}$ & $6.06 \pm 0.35^{* * *}$ \\
$\mathrm{Ni}+\mathrm{Sil}$ & $8.1 \pm 0.27^{* \# \# \#}$ & $44.22 \pm 1.45^{* \#}$ & $15.03 \pm 1.1^{\#}$ & $10.10 \pm 0.53^{\# \# \#}$ \\
\hline
\end{tabular}

Values are given as mean \pm SEM of seven rats each group. Statistically differences from control: ${ }^{*} \mathrm{p}<0.05,{ }^{* *} \mathrm{p}<0.01,{ }^{* * *} \mathrm{p}<0.001$; from $\mathrm{Ni}$ : ${ }^{\#} \mathrm{p}<0.05$, ${ }^{\# \# \#} \mathrm{p}<0.001$.

\section{Effect of treatments on hematological parameters}

Nickel treatment resulted in a significant decrease of red blood cells (RBCs) counts, platelet (Plt) counts and white blood cell (WBC) counts $(\mathrm{p}<0.001)$, hematocrit and hemoglobin $(\mathrm{Hb})$ concentration $(\mathrm{p}<0.01)$ in nickel group when compared to control group.

For the group treated with nickel associated with silymarin extract, the results showed a correction of anemia which was manifested by a significant increase in red blood cells (RBCs): $(p<0.001)$, hematocrit, heamoglobin and platelet counts: $(\mathrm{p}<0.05)$, an improvement of white blood cell $(\mathrm{WBC})$ count $(\mathrm{p}<0.001)$ compared to the group treated with nickel (table 3).

\section{Effects of treatments on kidney oxidative stress parameters}

As seen from fig. 1, the exposure to nickel led to an increase of MDA level $(\mathrm{p}<0.01)$, accompanied by a reduction $(\mathrm{p}<0.01)$ in $\mathrm{GSH}$ concentration in kidney compared to control group. These fig. also shows that the combination of silymarin extract administration to rats with nickel decreased the toxic effect of nickel in kidney, which were manifested by a reduction in MDA $(p<0.05)$ and an increase in GSH $(\mathrm{p}<0.01)$. The administration of nickel caused also a significant decline of SOD $(\mathrm{p}<0.01)$, GSH-Px $(\mathrm{p}<0.001)$ and catalase $(\mathrm{p}<0.01)$ activities (fig. 2). However, the co-administration of silymarin extract led also a recovery in these renal enzymes activities.
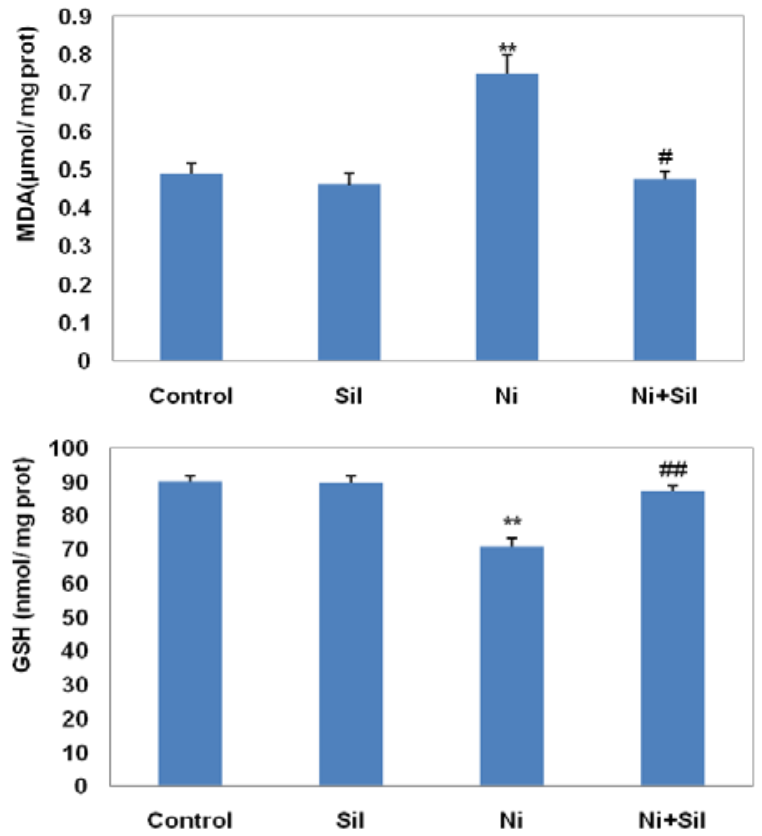

Fig. 1: MDA and GSH concentrations in the kidney of control rats, treated with $\mathrm{Sil}, \mathrm{Ni}$ and $\mathrm{Ni}+\mathrm{Sil}$ after three weeks of treatment, Values are given as mean \pm SEM of seven rats each group. Significantly differences from control: ${ }^{* *} \mathbf{p}<0.01$; from $\mathrm{Ni}$ : ${ }^{\#} \mathbf{p}<0.05,{ }^{\#} \mathbf{p}<0.01$
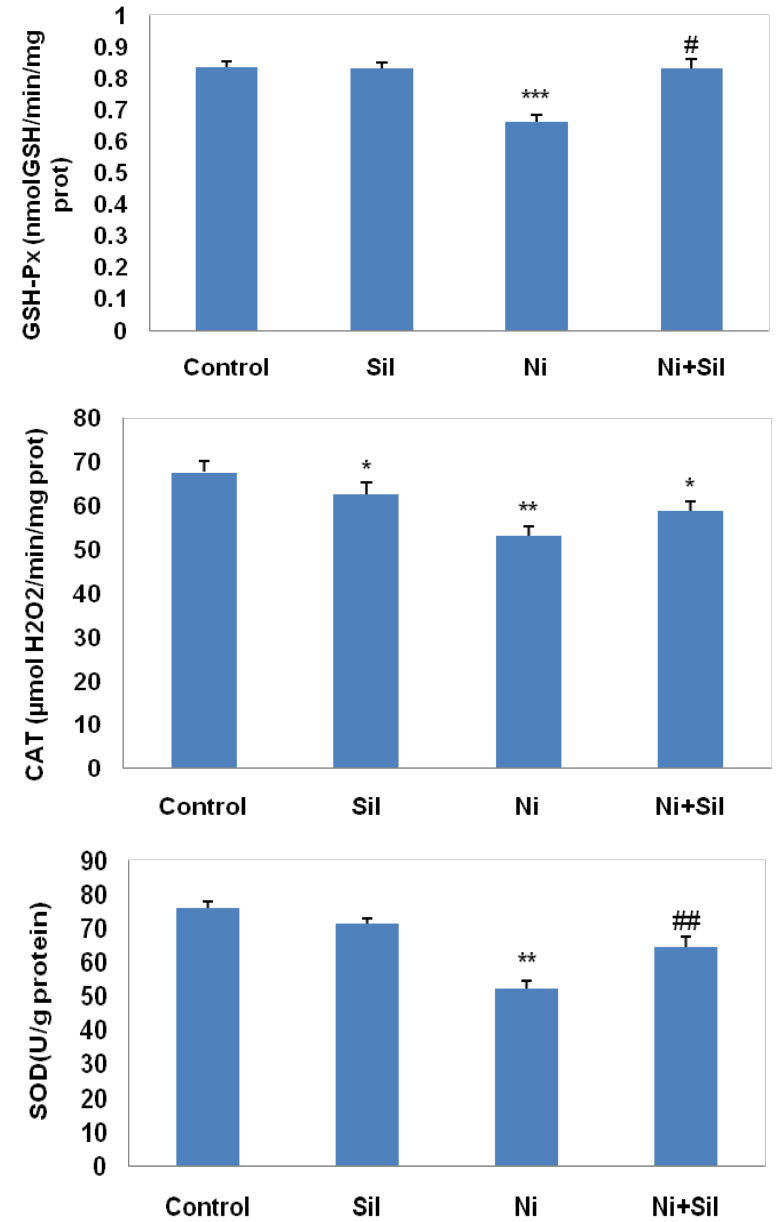

Fig. 2: GSH-Px, CAT and SOD activities in the kidney of contro rats, treated with $\mathrm{Sil}, \mathrm{Ni}$ and $\mathrm{Ni}+\mathrm{Sil}$ after three weeks of treatment, Values are given as mean \pm SEM of seven rats each group. Significantly differences from control: ${ }^{* *} \mathbf{p}<0.01,{ }^{* * *} \mathbf{p}<0.001$; from Ni: ${ }^{\#} \mathbf{p}<0.05,{ }^{\# \#} \mathbf{p}<0.01$

\section{Histopathology results}

Fig. 3 (A-D) demonstrates the histopathological examination of the kidney sections of control and the experimental rats. $\mathrm{H}$ and $\mathrm{E}$ kidney stained sections showed a normal histopathology of the glomeruli and tubules in the cortex and medulla in kidney section of both control and silymarin groups (fig. 3 A and B). Whereas, some nephrotoxic lesions were observed in nickel animals, which were indicated by congestions of the interstitial tissues, vacuolar and tubular necrosis (fig. 3C). On the other hand, the severity of the histopathological lesions in kidney was decreased due to the combined treatment with silymarin (fig. 3D). 

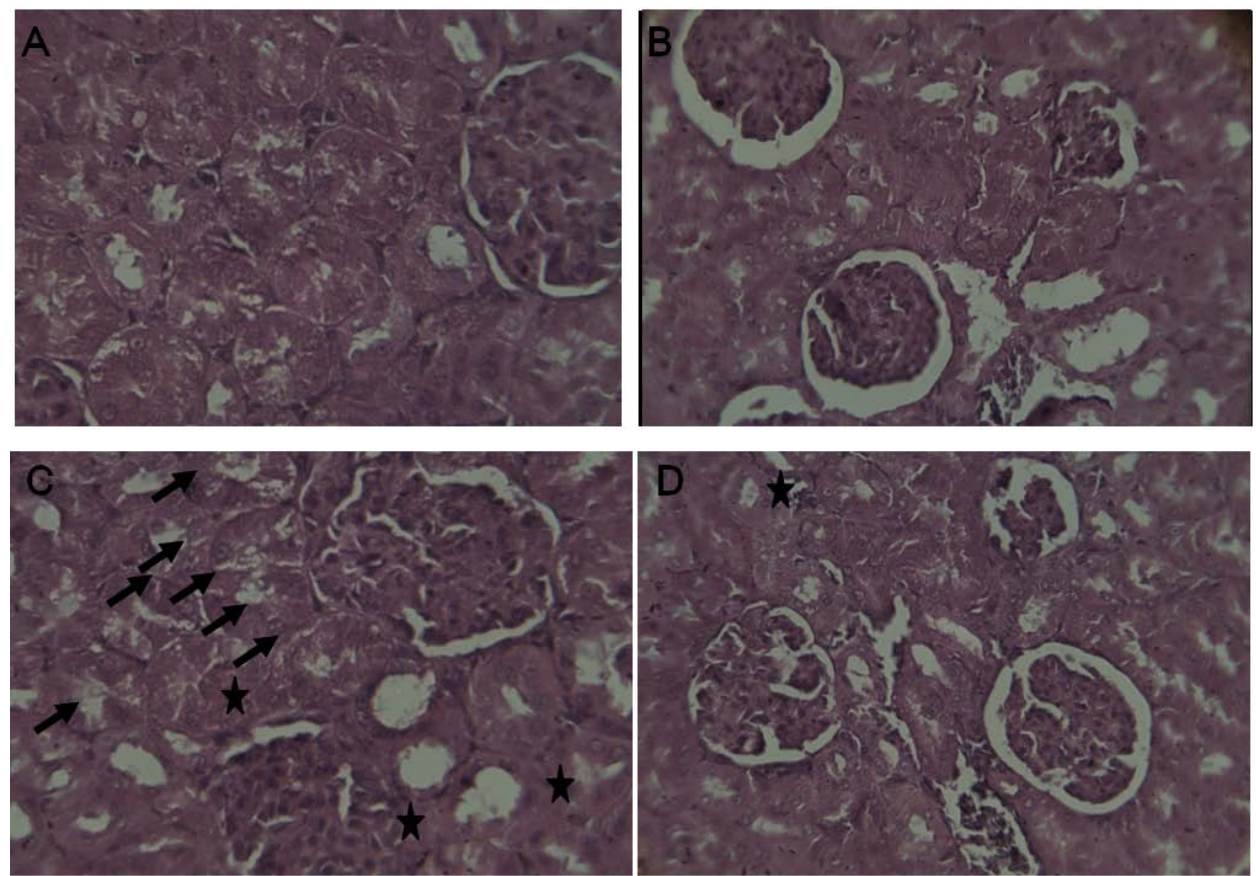

Fig. 3: Photomicrograph of kidney stained with (H \& E, ×400). (A) Normal morphology of the renal parenchyma with well-defined glomeruli and tubules, (B) Kidney section from silymarin extract treated rats showing nearly similar appearance to that of the control group. (C) Nickel sulfate exposed rats, showing cloudy swelling of tubules with congestions of the renal interstitium (arrows), vacuolar degeneration of tubular epithelial cells ( $\star$ ), (D) Kidney section from nickel sulfate and silymarin extract treated rats, showing almost normal appearance of glomeruli and tubules

\section{DISCUSSION}

It is known that kidney is the most target organ of toxicity [26]. A number of drugs, chemicals and heavy metals have been shown to alter its structure and function. Animal experiments and human studies are conclusive about metabolic adverse effects and nephrotoxicity of nickel compounds [27]. Silymarin, a very strong antioxidant compound, is well documented for the attenuation of oxidant mediated renal damage induced by various xenobiotics [28]. Therefore, this study was devoted to determine the beneficial effects of silymarin extract on nickel-induced kidney injury and heamatotoxicity in rats. According to the findings obtained, a significant reduction was observed in body weight of nickel exposed group. The decreased body weight is concomitant with previously reports [29]. This reduction in weights might as a result of the overall increased degeneration of lipids and proteins [30]. Findings indicated also an increase of absolute and relative kidney weights, which might be explained by the hypertrophy and the selective accumulation of nickel in the kidney [26, 31]. Nevertheless, these morphological changes observed in nickel administered rats were attenuated by treatment with the co-administration of silymarin. It was reported undoubtedly in many studies that silymarin has a significant protective effect against damage induced by heavy metals such as arsenic and cadmium [32, 33]. The measurements of creatinine, urea, and uric acid are considered a tool for clinical diagnosis of renal dysfunction following acute and chronic oxidative injury these markers are the end products of various metabolic pathways that are excreted in the urine via glomerular filtration whose serum levels are an indicator of renal functions [34]. So the significant augmentation in serum urea, creatinine and uric acid upon nickel exposure possibly as a result of cellular damage due to the excess free radical production [35], this testifies to the installation of renal insufficiency, and may result in a decrease in reabsorption at renal epithelium and disruption of glomerular filtration rate, which was seen in histopathological examination. In other words, the decline in glomerular filtration may be due to a decrease in the number of functional nephrons [36]. Mathur et al. [37] showed that nickel accumulates in the kidneys by inducing many lesions which the most common are hyperemia and parenchymal cell degeneration with necrotic foci. Furthermore, it was well documented that nickel mainly accumulates in kidney because these organ contain most of the metallothionein, a metal binding protein with high affinity for nickel [38].

The treatment with silymarin led to a protection against nickel induced nephrotoxicity, which was manifested by decreased plasma creatinine, urea and acid uric levels and normal histopathological sections. Similarly, previous investigations mentioned that siymarin protected against cisplatin-induced renal toxicity [39], lead [40] and adriamycin [41]. The improvement in the histopathological changes including the recovery of some glomeruli, the decrease in the congestion and inflammatory infiltration perhaps due to the contributory self-healing mechanism restoring the kidney structure and function [28].

The exposed to a nickel induced reduction in red blood cells counts, hematocrit, heamoglobin concentration, platelets counts. Thus, it was suggested that nickel may adversely affect the hematopoietic process and bone marrow activity resulting in a reduction of red blood cells and hemoglobin, which is likely due to iron deficiency or chemically induced anemia $[27,42]$.

Nickel is also found to induce oxidative injury in erythrocytes following generation of reactive oxygen species (ROS) [38]. In addition, the low hemoglobin concentration in this study may be as a result of a decrease in the succinyl and glycine pools, as well as the key enzymes such as, ALAD (Aminolevulinic Acid Dehydratase) that are required in the hem biosynthesis [43]. The leucopenia after nickel treatment may be attributed to the inhibition of white blood cell maturation, their release from tissue reservoir or occurrence of leucopoenia in an organism as a response to a stress caused by toxic compounds associated with allergic reaction [27]. A Surprisingly, the co-treatment with silymarin effectively attenuated the nickel induced alterations in the hematological variables and thereby protecting the heme from nickel induced oxidative stress, by it's effective antioxidative and free radical scavenging activities [44]. Nickel is well known to produce oxidative damage in the kidney by enhancing lipid peroxidation [45]. In biological systems, malondialdehyde (MDA), a degradation product of lipid 
hydroperoxides, this is considered as an index of lipid peroxidation. The data obtained in this study confirm that chronic intoxication with nickel caused an increase of LPO concentration in kidneys of rats as indicated by the significant increase in MDA. It has been reported that administration of nickel resulted in the accumulation of iron, which in turn generate ROS via Haber-Weiss and Fenton's reaction $[35,46]$. The significant decrease in reduced glutathione in nickel treated group was correspondingly with previous reports [47, 48]. The results showed also that nickel administration induced a significant decrease SOD, CAT and GSH-Px activities. This probably is the consequence of the intracellular accumulation of ROS with subsequent development of kidneys injury, and might be due to their increased utilization in scavenging free radicals induced by the metal, thus causing irreversible inhibition in their activities or due to direct binding of the metal to the active sites of these enzymes [49]. In other words, SOD was inhibited by hydrogen peroxide, while GSHPx and catalase were inhibited by an excess of superoxide radical [50]. It was noticed also that the co-treatment with silymarin provided a significant protection against nickel induced nephrotoxicity by decreasing the level of MDA and increasing GSH level. This could be attributed to the excellent antioxidant properties of silymarin [51]. This property seems to be due to its ability to scavenge free radicals. Moreover, Silymarin can result in elevation of glutathione levels through the maintenance of GSH homeostasis in the body [52]. This might be the reason for elevated glutathione levels observed during silymarin treatment. The administration of silymarin also significantly protected SOD and GSH-Px activities by directly scavenging ROS as well as by inhibiting lipid peroxidation. Ahmed et al. [53]. Reported that the protective effects of silymarin are mediated, in part by its antioxidant defence ability and the scavenging of free radicals; It has been also shown that silymarin has the ability to chelate with redox metals and to reduce lipid peroxidation by induction of both enzymatic and non-enzymatic antioxidants [51, 54].

\section{CONCLUSION}

The findings of this study demonstrated that the exposure to nickel provoked nephrotoxicity, disturbed the hematological and the renal antioxidant parameters. However, the coadministration of silymarin extract have ameliorative effects on these disturbances caused by nickel, which probably through its antioxidant properties and inhibiting ROS generation.

\section{ACKNOWLEDGMENT}

This study was supported by a research project under the number: F01120140045 funded by the ministry of Higher Education, Algeria. Authors thank Pasteur Institute, Algiers for providing rats.

\section{AUTHORS CONTRIBUTION}

Zine Kechrid formulated the present hypothesis. Abdelfattah Elfki Contributed by the analysis of some parameters in his laboratory. Zine Kechrid and Samira Bouhalit were responsible for writing the report. Samira Bouhalit was also responsible for the analysis of the data.

\section{CONFLICT OF INTERESTS}

Authors declare no conflict of interest

\section{REFERENCES}

1. The International agency for research on cancer. Nickel and nickel compounds. In: Chromium, nickel and welding. Vol. 49. IARC, Lyon, France, IARC monographs on the evaluation of carcinogenic risks to humans; 1990. p. 257-445.

2. Kang GS, Gillespie PA, Gunnison A, Moreira KM, Chen LC. Longterm inhalation exposure to nickel nanoparticle sex acerbated atherosclerosis in a susceptible mouse model. Environ Health Prespect 2011;119:176-81.

3. Maha AF, Nagwa HH, Farouk R, Zeinab MH, Hanan AA. Studies on the genotoxic effect of nickel chloride in mice and the possible protective role of soybean seeds extracts. Global J Pharmacol 2014;8:625-34.

4. Minigaliyeva IA, Katsnelson BA, Privalova LI, Gurvich VB, Panov $\mathrm{VG}$, Varaksin AN, et al. Toxicodynamic and toxicokinetic descriptors of combined chromium (VI) and nickel toxicity. Int J Toxicol 2014;33:498-505.

5. Severa J, Vyskocil A, Fiala Z, Cizkova M. Distribution of nickel in body fluids and organs of rats chronically exposed to nickel sulphate. Hum Exp Toxicol 1995;14:955-8.

6. Berndt WO. In: Anders MW, Dekant W, Henschler D, Oberleithner H, Silbernag S. Renal Disposition and Nephrotoxicity of Xenobiotics. San Diego, Academic Press; 1993. p. 269-88.

7. Huang X, Zhuang Z, Frenkel K, Klein CB, Costa M. The role of nickel and nickel-mediated reactive oxygen species in the mechanism of nickel carcinogenesis. Environ Health Perspect 1994;102:281-4.

8. Wang YF, Shyu HW, Chang YC, Tseng WC, Huang YL, Lin KH, et al. Nickel (II)-induced cytotoxicity and apoptosis in human proximal tubule cells through a ROS and mitochondriamediated pathway. Toxicol Appl Pharmacol 2012;259:177-86.

9. Dieter MP, Jameson CW, Tucker AN, Luster MI, French JE, et al. Evaluation of tissue disposition, myelopoietic and immunologic responses in mice after long-term exposure to nickel sulphate in the drinking water. J Toxicol Environ Health 1988;24:356-72.

10. Adjroud 0, Mouffok S. Effects of nickel chloride on hematological and developmental parameters in wistar albino pregnant rats. Ass Univ Bull Environ Res 2009;12:1-9.

11. Radak Z, Sasvari M, Nyakas C, Kaneko T, Tahara S, Ohno H, et al. Single bout of exercise eliminates the immobilization-induced oxidative stress in rat brain. Neurochem Int 2001;39:33-8.

12. Kiruthiga PV, Shafreen RB, Pandian SK, Arun S, Govindu S, Devi KP. Protective effect of silymarin on erythrocyte haemolysate against benzo (a) pyrene and exogenous reactive oxygen species (H202) induced oxidative stress. Chemosphere 2007;68:1511-8.

13. Jalali SM, Najafzadeh H, Mousavi SM. Comparative effect of silymarin and d-penicillamine on lead induced hemotoxicity and oxidative stress in rat. Iranian J Toxicol 2017;11:11-8.

14. Katiyar SK. Silymarin and skin cancer prevention: antiinflammatory, antioxidant and immunomodulatory effects. Int J Oncol 2005;26:169-76.

15. Abdel-Gawad SK, Mohamed A. Silymarin administration protects against cisplatin-induced nephrotoxicity in adult male albino rats (Histological and Immunohistochemical Study). Egyptian J Histol 2010;33:683-91.

16. Aslam SN, Jahan S Ali, Rahman KU. An innovative microwaveassisted extraction and antioxidant potential of polyphenols from different parts of Ocimum basilicum. J Med Plants Res 2012;6:2150-9.

17. Shaker E, Mahmoud H, Mnaa S Silymarin. The antioxidant component and Silybummarianum extracts prevent liver damage. Food Chem Toxicol 2010;48:803-6.

18. Das KK, Dasgupta S. Effect of nickel sulfate on testicular steroidogenesis in rat during protein restriction. Environ Health Perspect 2002;110:923-6.

19. Yagi K. A simple fluorometric assay for lipoperoxide in blood plasma. Biochem Med 1976. p. 212-6.

20. Ellman GL. Tissue sulfhydryl groups. Arch Biochem Biophys 1959;82:70-7.

21. Giannopolitis CN, Ries SK. Superoxide dismutases; I occurrence in higher plants. Plant Physiol 1977;59:3009-14.

22. Aebi H. Catalase in vitro. In: Packer L. $2^{\text {nd }}$ ed. Methods in Enzymology. Academic Press: Orlando; 1984;105:121-6.

23. Paglia DE, Valentine WN. Studies on quantitative and qualitative characterization of erythrocyte glutathione peroxidase. J Lab Med 1967;70:158-69.

24. Bradford M. A rapid and sensitive method for the quantities of microgram quantities of protein utilizing the principle of protein binding, Anal Biochem 1976;72:248-54.

25. Haoult R. Techniques d'histopathologie et de cytopathologie. Ed Maloine 1984;19:225-7.

26. Kubrak O, Husak VV, Rovenko BM, Poigner H, Mazepa MA, Kriews $\mathrm{M}$, et al. Tissue specificity in nickel uptake and induction of oxidative stress in kidney and spleen of goldfish Carassius auratus, exposed to waterborne nickel. J Aquatic Toxicol 2012;118-119:88-96. 
27. Das KK, Das SN, Dhundasi SA. Nickel, its adverse health effects and oxidative stress. Indian J Med Res 2008;128:412-25.

28. Amien AI, Fahmy SR, Abd-Elgleel FM, Elaskalany SM. Renoprotective effect of Mangifera indica polysaccharides and silymarin against cyclophosphamide toxicity in rats. J Basic Appl Zool 2015;72:154-62.

29. Amudha K, Pari L. Beneficial role of naringin, a flavonoid on nickel-induced nephrotoxicity in rats. Chem Biol Interact 2011;193:57-64.

30. Sidhu P, Garg ML, Dhawan D. Protective role of zinc in nickel induced hepatotoxicity in rats. Chem Biol Interact 2004;150:199-209.

31. Obone E, Chakrabarty SK, Bai C, Malick MA, Lamantagne L, Subramanian KS. Toxicity and bioaccumulation of nickel sulphate in Sprague-Dawley rats following $13 \mathrm{w}$ of subchronic exposure. J Toxicol Environ Health 1999;57:379-401.

32. Sabiu S, Sunmonu TO, Ajani EO, Ajiboye TO. Combined administration of silymarin and vitamin $\mathrm{C}$ stalls acetaminophen-mediated hepatic oxidative insults in Wistar rats. Rev Bras Farmacogn 2015;25:29-34.

33. Ahmed OM, Mahmoud AM, Abou Zid SF, Saber NY. Silymarin and hydroethanolic extracts of Silybum marianum leaves and fruits attenuate diethylnitrosamine/phenobarbital-induced nephrotoxicity via their antioxidant and anti-inflammatory actions. Am J Biochem 2016;6:21-9.

34. Anusuya N, Durgadevi P, Dhinek A, Mythily S. Nephroprotective effect of ethanolic extract of garlic (Allium sativum L.) on cisplatin induced nephrotoxicity in male wistar rats. Asian J Pharm Clin Res 2013;6 Suppl 4:97-100.

35. Stohs SJ, Bagchi D. Oxidative mechanisms in the toxicity of metal ions. Free Radical Biol Med 1995;8:321-36.

36. Chinnala KM, Achanta P, Vangala VL, Elsani MM. Evaluation for the nephroprotective activity of ethanolic extract of Allium cepa Linn. in gentamicin-induced nephrotoxicity in rats. Asian J Pharm Clin Res 2017;10:356-9.

37. Mathur AK, Gupta BN, Singh A, Shanker R. Renal toxicity of nickel, sodium lauryl sulfate and their combination after dermal application in guinea pigs. Biomed Environ 1993;6:231-6.

38. Novelli ELB, Hernandes RT, Novelli Filho JLVB, Barbosa LL. Differential/combined effect of water contamination with cadmium and nickel on tissues of rats. Environ Pollut 1998;103:295-300.

39. Karimi G, Ramezani M, Tahoonian Z. Cisplatin nephrotoxicity and protection by milk thistle extract in rats. Adv Access Pub eCAM 2005;2:383-6.

40. El-Khishin IA, El-fakharany YMM, Abdel Hamid OI. Role of garlic extract and silymarin compared to dimercaptosuccinic acid (DMSA) in the treatment of lead induced nephropathy in adult male albino rats. Toxicol Rep 2015;2:824-32.

41. El-Shitany NA, El-Haggar S, El-desoky K. Silymarin prevents adriamycin-induced cardiotoxicity and nephrotoxicity in rats. Food Chem Toxicol 2008;46:2422-8.

42. Tikare SN, Yendigeri S, Das Gupta A, Dhundasi SA, Das KK. Effect of $\alpha$-tocopherol against hematotoxicity, hepatotoxicity and nephrotoxicity induced by nickel sulfate in male albino rats. Indian J Physiol Pharmacol 2013;57:280-92.

43. Das Gupta A, Das SN, Dhundasi SA, Das KK. Effect of garlic (Allium sativum) on heavy metal (nickel II and chromium VI) induced alteration of serum lipid profile in male albino rats. Int J Environ Res Public Health 2008;5:147-51.

44. Abid Ali WDh, Khudair ARN, AL-Masoudi EA. Influence of silymarin extracted from Silybum marianum seeds compared to legalon against nickel chloride induced hematological and biochemical changes in male rabbits. Bas J Vet Res 2015;14:293-305.

45. Boulila S, El Feki A, Oudadesse H, Kallel C, El Feki H. Detoxification of rats subjected to nickel chloride by a biomaterial-based carbonated orthophosphate. Pharmaceutica 2014;72:348-62.

46. Cempel M, Nikel G. Nickel: a review of its sources and environmental toxicology. Pol J Environ Stud 2006;15:375-82.

47. Pari L, Prasath A. Efficacy of caffeic acid in preventing nickel induced oxidative damage in liver of rats. Chem Biol Interact 2008;173:77-83.

48. Chen CY, Wang YF, Lin YH, Yen SF. Nickel-induced oxidative stress and effect of antioxidants in human lymphocytes. Arch Toxicol 2003;77:123-30.

49. Sun $\mathrm{H}, \mathrm{Wu}$ W, Guo J, Xiao R, Jiang F, Zheng L, et al. Effects of nickel exposure on testicular function, oxidative stress and male reproductive dysfunction in Spodoptera litura Fabriciu. Chemosphere 2016;148:178-87.

50. Reham ZH, Mohammad SA. Amelioration of paracetamol hepatotoxicity and oxidative stress on mice liver with silymarin and extract supplements. Asian Pac J Trop Biomed 2015;5:521-31.

51. Jain A, Yadav A, Bozhkov AI, Padalko VI, Flora SJS. Therapeutic efficacy of silymarin and naringenin in reducing arsenicinduced hepatic damage in young rats. Ecotox Environ Safe 2011;74:607-14.

52. Shaarawy SM, Tohamy AA, Elgendy SM, Elmageed ZY, Bahnasy A, Mohamed MS, et al. Protective effects of garlic and silymarin on NDEA-induced rat's hepatotoxicity. Int J Biol Sci 2009;5:549-57.

53. Ahmad I, Shukla S, Kumar A, Singh BK, Kumar V, Chauhan AK, et al. Biochemical and molecular mechanisms of $\mathrm{N}$-acetyl cysteine and silymarin-mediated protection against maneb and paraquat-induced hepatotoxicity in rats. Chem Biol Int Chem Biol Interact 2013;201:9-18.

54. Ramadan SI, Shalaby MA, Afifi N, El-Banna HA. Hepatoprotective and antioxidant effects of Silybum marianum plant in rats. Int J Agric Vet Med Sci 2011;5:541-7.

\section{How to cite this article}

- Samira Bouhalit, Zine Kechrid, Abdelfattah Elfeki. Effect of silymarin extracted from Silybum marianum on nickel hematotoxicity and nephrotoxicity in male albino wistar rats. Int J Pharm Pharm Sci 2017;9(8):84-89. 